\title{
The Dog in the Lifeboat Revisited
}

\author{
Judith Barad-Andrade \\ Indiana State University
}

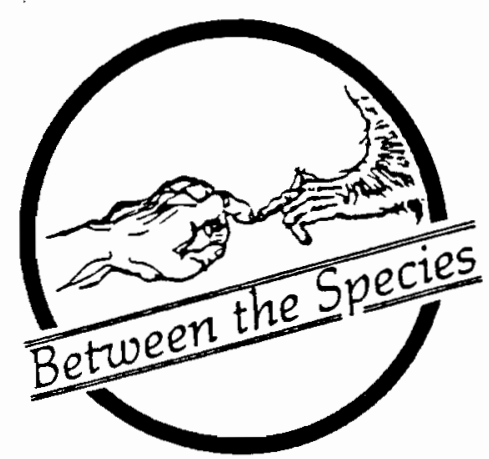

Editors' Note: This essay and the commentary on it by Professor Finsen were presented at the Pacific Division Meetings of the American Philosophical Association, held in San Francisco, California, March, 1991. Professor Barad's paper was originally written at the invitation of the editors of Etica \& Animali. We thank them for permission to publish the English version of the essay.

The Case for Animal Rights by Tom Regan provides a very cogent argument for attributing rights to animals. Most of the students in my Ethics and Animals course, for whom it is a required text, find it quite convincing. Those students who are predisposed to acknowledge that animals have rights feel assured and vindicated by reading Regan's arguments. However, their happy response is abruptly altered when, in the final weeks of the course, they read the passage describing four normal adults and a dog in a lifeboat. Regan argues that supposing one must be sacrificed or all will die, it should be the dog. He adds that this choice should be made even if the decision were between four humans and a million dogs, though all have equal inherent value. This passage, extremely disconcerting to some of my students, evokes much discussion both in and out of the classroom. In this paper I will explore whether or not my students' agitation can be philosophically supported. I will first discuss the argument as advanced by Regan, then turn to the principles on which it is based, and finally critically examine both the argument and its principles.

The lifeboat situation is such that we have only two choices: since the boat only has enough room for four

individuals and there are five survivors, either one must be sacrificed or else all must die. Regan assumes that our prereflective intuition is that the dog must die. ${ }^{1}$ And he supports this intuition by appealing to the worse-off principle, which states the following:

Special considerations aside, when we must decide to override the rights of the many or the rights of the few who are innocent, and when the harm faced by the few would make them worse-off than any of the many would be if other options were chosen, then we ought to override the rights of the many. ${ }^{2}$

In other words, in cases where we must choose between harming one innocent or harming another, and the harms are not prima facie comparable, we should override the right of that individual who will be harmed less. In situations calling for a decision in which there is a disjunctive dilemma, the individual who will be harmed less should suffer rather than the individual who will be harmed more. Illustrating this principle, Regan considers two people, one facing death and the other a migraine. ${ }^{3}$ The individual who faces death would be harmed much more than the individual who may suffer a migraine. These harms are not prima facie comparable. According to the worse-off principle, we must choose to override the

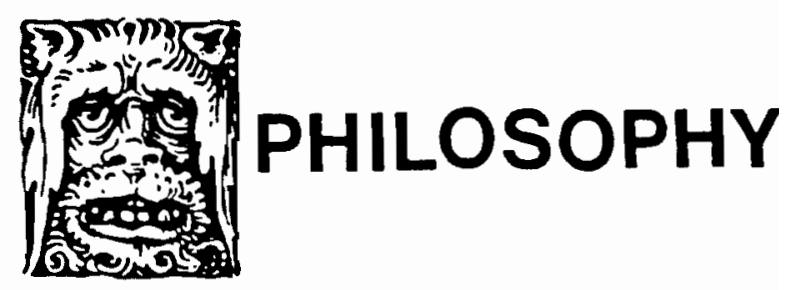


right of the person about to suffer a migraine rather than to override the right of the person facing death. To make the opposite choice or to flip a coin in this matter would be to treat the person about to suffer a migraine with more respect than he is due. ${ }^{4}$

Regan applies the worse-off principle to the lifeboat case by claiming that each human being would be made worse off by dying than the dog would be if he were thrown overboard. Although all five individuals would be harmed by dying, the death of the dog is a lesser harm, Regan argues, because death is a harm inasmuch as it forecloses opportunities for satisfaction, and the humans would lose more of these opportunities than the dog would lose. Regan says, "Death for the $\operatorname{dog} . .$. though a harm, is not comparable to the harm that death would be for any of the humans." 5 In short, since the dog's death is a lesser harm than the death of any normal adult, the dog should be killed. To save the dog or to flip a coin would be to count the lesser harm done to the dog as equal to or greater than the harm done to the humans.

One notion crucial to the life-boat situation and the worse-off principle is that of comparable harm. It underlies the worse-off principle, since the principle only applies when harms are not comparable. Prior to the life-boat passage, Regan discusses what he means by "comparable" harm, claiming that "Two harms are comparable when they detract equally from an individual's welfare, or from the welfare of two or more individuals." ${ }^{6}$ For instance, death is a comparable harm for two individuals if they would each lose an equal amount of opportunities for doing what will bring them satisfaction. But death is not a comparable harm when one individual suffers a greater magnitude of loss than the other. Regan says, "The untimely death of a woman in the prime of her life is a prima facie greater harm than the death of her senile mother." Consequently, the death of the mother is not comparable to the harm that death would be for the daughter. In a situation where only one could be selected to live, the worse-off principle would require us to override the right of the mother to live.

Having given an overview of Regan's life-boat argument and the principles on which it is based, his reasoning can now be evaluated. The worse-off principle, as Regan notes, is derivable from the respect principle. ${ }^{8}$ According to the respect principle, we must treat an individual with the respect she is due as a matter of strict justice. Two individuals who have equal inherent value should be treated with equal respect. But when these individuals are to be harmeci in different degrees, and only one can be rescued from harm, then out of respect for both we should rescue that individual who will be harmed more. The worse-off principle is strong and well-supported as a formal principle.

However, in practical applications the worse-off principle may be too vague to indicate the correct moral decision. The vagueness of the worse-off principle is attributable to the notion of comparable harm contained in it. The problem with the notion of comparable harm is that it must be assessed in specific, individual circumstances, and this is not always an easy matter. In some cases the assessment of comparable harm is quite clear, as in the example of the person about to suffer a migraine and the person about to die. There is no doubt which harm is worse, restricting our evaluation to the individuals involved, even if the person facing an untimely death is a homeless hermit and the person facing a migraine is the President of the United States. But Regan's example of the senile mother and daughter in the prime of life does not as clearly illustrate the notion of comparable harm. First, it is not clear whether the mother's death is less of a harm because she is senile or because she is much older than the daughter. Let us suppose that Regan is claiming that the mother's death is less of a harm than her daughter's death both because she is senile and much older. Is this claim as lucid and forceful as the claim that one who suffers a migraine is harmed less than one who suffers death?

An assumption underlying this claim is that a senile person has less opportunities she can satisfy than a person in full control of her mental faculties. The same assumption plays a role in deciding that death is a greater harm for a younger individual than for an older one. But should this assumption be taken for granted in both cases?

For Regan, death is a harm because it forecloses opportunities for satisfaction. ${ }^{9}$ But the phrase "opportunities for satisfaction" is ambiguous. It can either mean potentials for satisfaction in the sense of logical possibilities or it can refer to chances for satisfaction based on a favorable combination of current circumstances. But Regan recognizes the "well-known problems involved in inferring what is actual from what is potential." ${ }^{10} \mathrm{He}$ illustrates these problems in the following example:

When Henry Aaron was a wee toddler it was true that he was potentially the person who 
would set a record for the most career home runs hit in major league baseball, and, as things turned out, he actually set this record. But it does not follow that the wee-toddler, who is Henry Aaron at that time actually holds this record. ${ }^{11}$

Since Regan does not think we should infer what is actual from what is potential, it is highly probable that when he discusses "opportunities for satisfaction," he is not referring to potential opportunities for satisfaction in the sense of logical possibilities. The phrase most likely refers to chances for satisfaction based on a favorable combination of current circumstances.

Given this more precise meaning, is it necessarily true that an older person possesses fewer opportunities for satisfaction than a younger person? It is not very difficult to imagine that a mother may be an intellectually gifted researcher, a talented artist, and an active social reformer who takes great joy in all her achievements, while her daughter is intellectually bereft, has no talents, and is only interested in partying. Which person has greater opportunities for satisfaction? If we are only considering chances for satisfaction based on a favorable combination of characteristics and current circumstances, the answer is clear. There is no basis, other than an extremely speculative one, for holding that the daughter's opportunities for satisfaction are greater than the mother's opportunities for satisfaction.

Focusing on the mother's senility as grounds for saying that she has less opportunities than the daughter, it is important to consider the degree of her impairment. A severely impaired senile person, one who cannot remember anything from one minute to the next, may indeed have less opportunities for satisfaction than a person with unimpaired faculties. But this may not be true of a person who is moderately senile. In order to better illustrate the problem with the notion of comparable harm, let us suppose that the mother is only moderately senile.

Attributing this lesser degree of senility to the mother gives her a moral status comparable to the dog, i.e., both the dog and the senile mother are moral patients. Regan distinguishes two types of moral patients: (a) those individuals who are conscious and sentient and (b) those individuals who are not merely conscious and sentient but

who have desires and beliefs, who perceive, remember, and can act intentionally, who have a sense of the future, including their own future, who have an emotional life, who have a psychophysical identity over time, who have a kind of autonomy, and who have an experiential welfare. ${ }^{12}$

Since the dog is a moral patient in the second sense, let us suppose that the senile mother is also a moral patient in this sense. Does her mental impairment foreclose certain opportunities to her? Certainly! She might not be able to take a college course, read the newspaper, or carry on a sustained conversation. But is it possible that her daughter, a normal adult human being, has either an equal amount of opportunities for satisfaction or even fewer? Again, the sort of opportunities under discussion are not opportunities in the sense of logical possibilities in the future but chances for satisfaction based on a favorable combination of characteristics and current circumstances. Would the daughter, an assembly-line worker who lives alone and who watches television after work until she goes to bed, only varying her routine on week-ends and holidays by not working, have more opportunities for satisfaction than her mildly senile (she can remember to a limited extent) mother who socializes with many friends, enjoys taking walks, investigating new places, and who relishes amusement parks? As in the case of an older person vs. a younger person, if we are only considering chances for satisfaction based on a favorable combination of characteristics and current circumstances, the senile mother has more opportunities for satisfaction.

Returning to the five survivors in the lifeboat, we can ask the same question. Suppose the four normal adult human beings work in the same assembly line as the aforementioned daughter, have a cynical attitude toward life, are companionless, and when not at work can almost always be found in front of the television set. Of course, there are individual variations, but none affect their current circumstances in a substantial way. Now suppose that the dog has close ties with her human family, has puppies waiting for her at home, enjoys riding in the car and long walks, and has an interest in investigating new places and meeting new creatures. Moreover, in addition to this dog's friendliness and acute curiosity, suppose that a year ago this dog displayed her courage and loyalty by rescuing a young friend from a burning building. If all five individuals have equal inherent value, and if death is a harm to each of them because it would foreclose opportunities for satisfaction, 
which of the five individuals would be harmed most by dying? If the dog would be harmed more, then the worse-off principle requires that one of the others should be selected to die rather than the dog.

The primary problem with the notion of comparable harm, as used by Regan, is that he correctly formulates it to apply to individuals ${ }^{13}$ but then applies it to groups: old groups, young groups, senile groups, dog groups, and normal human groups. Although individuals within a group share certain characteristics, in some ways they may be very different. And the differences among individuals may be morally relevant for those who make decisions about them in specific situations. Not all senile individuals, for example, have the same opportunities for satisfaction. Some may have a great many such opportunities, whereas others may have few. And the same is true for young individuals, dogs, and normal adult humans. In trivial matters it may be more convenient to lump all the individuals of a certain group together, but in life and death situations it is a matter of justice to consider each individual's opportunities for satisfaction independent of the group she belongs to. It may be the case that Fido should be thrown overboard rather than Sally, Sam, Joe or Fred. But if all have equal inherent value, and if we are to avoid speciesism, we must consider Fido's opportunities for satisfaction to be fewer than the others' opportunities based on his current circumstances as Fido and not as a dog.

One problem with this solution is that in life and death situations we may not have the time to weigh each individual's opportunities for satisfaction. Connected to this problem is the fact that all five survivors may be strangers to each other. The dog cannot talk about her background; another survivor may be mute; and the other three may be liars. Another problem is human error in assessing which current circumstances may engender opportunities for satisfaction. But to judge opportunities for satisfaction in life or death situations without seriously examining each individual's opportunities for satisfaction as individuals is to give each survivor less respect than he is due. Giving an individual less respect than he is due is a violation of the respect principle. And to assess opportunities for satisfaction by assuming that all members of a given species have the same opportunities for satisfaction and that the human species has more opportunities than the canine species is to fall into speciesism.

Anticipating an objection of this sort, Regan claims that the life-boat decision is not speciesist because "it is based on assessing the losses each individual faces and assessing these losses equitably." ${ }^{14}$ But nowhere in the life-boat passage do we find any attempt to do this. Rather, Regan assesses the losses Fido faces as a representative of "doghood" as opposed to the losses the other four survivors face as representatives of humanity. To make matters worse, by insisting that the four humans should be saved at the expense of a million dogs, Regan even more emphatically implies that the individual circumstances, characteristics, and hence opportunities for each of a million dogs should not be taken into account. This approach is quite inconsistent with the rights view's overall concern with the individual. If Regan is to avoid both inconsistency and speciesism, he must either amend the life-boat decision or take into account the individual differences among the survivors to justify his initial decision. This criticism is not merely a semantic matter, for it makes all the difference whether a life and death decision is based on an individual's rights as an individual or his rights as a member of a species. If such a decision is based on one's rights as a member of a species, Regan's argument collapses. Thus it seems that my students prereflective and considered intuitions were well-founded.

\section{Notes}

${ }^{1}$ Tom Regan, The Case for Animal Rights (California: University of California Press, 1983), p. 324.

${ }^{2}$ Ibid., p. 308.

${ }^{3}$ Ibid., p. 309.

${ }^{4}$ Ibid.

${ }^{5}$ Ibid., p. 324.

${ }^{6}$ Ibid., p. 304.

${ }^{7}$ Ibid., p. 303.

${ }^{8}$ Ibid., p. 308.

${ }^{9}$ Ibid., p. 99; 324.

${ }^{10}$ Ibid., p. 16.

${ }^{11}$ Ibid.

${ }^{12}$ Ibid., p. 153.

${ }^{13}$ Ibid., p. 304.

$14 \mathrm{Ibid}$, p. 325. 